\title{
Assessment of Mortality among Patients Utilizing Emergency Medical Services of Tertiary Care Hospital, Pune
}

\author{
Rajhans Prasad A1 , Kulkarni Priya Y2, Kelkar Dhananjay S³, Jog Sameer A4, Ranade Gouri5, \\ Utpat Sonal ${ }^{6}$, Hande Varsha ${ }^{7}$
}

${ }^{1} \mathrm{MD}$ (Anaesthesia) FICCM,Chief Intensivist, ${ }^{3} \mathrm{MS}$ (Surgery), Medical director, ${ }^{4} \mathrm{MD}$ (Medicine), Consultant Intensivist, ${ }^{5} \mathrm{DNB}$ (Anaesthesia), Consultant Intensivist, ${ }^{6} \mathrm{MD}$ (Medicine), Head of Emergency Department, ${ }^{7}$ Senior emergency medical officer, Deenanath Mangeshkar Hospital and Research Centre, Pune, India.

${ }^{2}$ MD(Community Medicine), Associate Professor, Community Medicine, SMBT Medical College, Nasik, India.

\begin{abstract}
Background: Lot of progress has been made in emergency medical services in India. Assessment of mortality among patients utilizing emergency medical services is necessary.

Aim: To assess the mortality among patients utilizing emergency medical services based on their severity and purpose to call emergency medical services.

Material \& Methods: It was hospital record based study. Proforma enlisting required socio-demographic and clinical parameters of the patients was developed for data collection. A person with medical background was trained to extract required data. Glassgow coma scale was used to assess severity of the patients. Patients with incomplete records were excluded. Data were entered in Microsoft excel and imported in SPSS 15.0 software for analysis. Frequencies and proportions were enlisted. Associations were tested by Chi squared test.

Results: 849 patients were enrolled. $39.75 \%$ were females, $61.0 \%$ were males. Mean age 62.56 years $( \pm 20.76)$. Ambulance services reached at scene within 25 minutes in $75 \%$ cases. Highest number $(38.4 \%)$ of patients had altered sensorium. $28 \%$ of the patients were in severe category and majority $(62 \%)$ were in mild to moderate category. $9.7 \%$ patients with mild to moderate category died while $12.3 \%$ (27/212) severe category of patients died, difference in mortality was not significant $(p=0.220, O R=1.266,95 \% \mathrm{Cl}=$ 0.814-1.969). Highest percentage of deaths among severe
\end{abstract}

\section{INTRODUCTION}

Medical emergencies and accidents are on rise in India. ${ }^{1}$ Growing population, increased life expectancy, changing age structure, urbanization, lifestyle changes are all the reasons behind it. ${ }^{2}$ To take care of growing medical emergencies, efforts are being made to expand Emergency medical services (EMS) and to make it easily accessible from all the levels. "Dial 108 service" in India, is a nationwide initiative to support emergency ambulance services ${ }^{1}$. It is based on the basic fundamental principle of EMS systems to have a common emergency communication number connected to responsive agencies. ${ }^{3}$ The effective transport component is also contributing to reduction in maternal and infant mortalities and will help to achieve various Millennium Development Goals. ${ }^{1}$

But prior to the government efforts, some private agencies started EMS services in Chennai, Mumbai, Pune etc. ${ }^{3}$ Deenanth Mangeshkar Hospital (DMH) and Research centre, Pune, Maharashtra is one of the pioneering institution to set up EMS services in Maharashtra as early as in 1999 where the present study is carried out. ${ }^{4}$

Patients who receive basic care from trained professionals and is
GCS category was recorded in patients with road traffic accidents (VIII) and seizures (XI).

Conclusion: Emergency medical services help to reduce mortality among severe category of to the extent that reported in mild to moderate category. Patients with road traffic accidents need other provisions for prompt \& effective management. Relatives or persons accompanying known seizure patients can be educated about emergency measures taken in seizure episodes.

Key Words: EMS, GCS, Mortality.

${ }^{*}$ Correspondence to:

Dr Kulkarni Priya Y, 5, Shanti Sadan, Tarte Colony, Erandawane, Pune.

Email: dr_pdkulkarni@yahoo.co.in

Article History:

Received: 27-04-2016, Revised: 02-05-2016, Accepted: 20-05-2016

\begin{tabular}{|l|c|}
\hline \multicolumn{2}{|c|}{ Access this article online } \\
\hline $\begin{array}{l}\text { Website: } \\
\text { www.jimrp.com }\end{array}$ & Quick Response code \\
DOI: & \\
10.21276/ijmrp.2016.2.3.038 & \\
\hline
\end{tabular}

transported to the nearest healthcare facility within 15-20 minutes of an emergency has the greatest chance of survival. Hence it is called as 'Golden hour' which typify the importance of Emergency Medical Services (EMS) all over the world.5,6 Appropriate management of critical patient utilizing Golden Hour enhance survival, control morbidity and prevent disability. ${ }^{5}$

For rapid assessment, emergency physicians often use the Glasgow Coma Scale (GCS) to decide further management of critical patient. ${ }^{7}$ It measures patient's best eye, motor and verbal responses. It is widely used and accepted prognostic indicator for both traumatic and non-traumatic patients. ${ }^{8}$ The score has been validated for its inter-observer reliability, which improves with training and experience in different scenarios. ${ }^{9}$ It is taken as index of how patient is critical ${ }^{10}$ and predictor of outcomes, mortality or disability as they are related to scores. ${ }^{11,12}$ It is also used a to evaluate response to ongoing treatment. Though, originally derived for head injury patients to describe level of consciousness, most emergency ambulance services use the GCS in their paramedic patient assessment. ${ }^{12}$ 
Mortality among severe and mild to moderate GCS patients brought by EMS of DMH is studied in the present study. DMH has initiated its first ambulance service as early as in 1999 with its sister concern hospital. ${ }^{4}$ Intensivists from this hospital have their valuable contribution in the development of Maharashtra Emergency Medical Services (MEMS) which was launched in 2014 by government of Maharashtra, India. ${ }^{13}$ Initially DMH got 105 number to be dialed by government. Institute is offering internship programme for PG -diploma EMS students. ${ }^{14}$ Till today, DMH has excellent network of EMS in the catchment area. Ambulance personals are well trained to assess and manage critical patients while transportation.

\section{MATERIAL \& METHODS}

It was a retrospective study based on hospital records. Study was carried out in Deenanth Mangeshkar Hospital and Research centre having its own emergency ambulance services. Ethical approval was saught from Institutional ethical committee. Study subjects were patients who utilized EMS run by DMH during the year 2014. Proforma enlisting all the required information was developed for data collection. General information of the study subjects regarding demographic characteristics, emergency medical situation, patients' chief complaints, observations on general examination, GCS score, management during transportation and all the relavant information was gathered from ambulance call register and scanned copies of hospital records of ER sheets. Final outcome of patients was recorded from discharge summaries if patient was admitted to DMH itself and from transfer forms if shifted to other hospitals. Individual components of GCS score i. e. eye opening, verbal and motor responses were scored on EMS forms by ambulance personals. They were summed up to get GCS score. Study subjects died at the scene, before or after arrival of ambulance and emergency team or with incomplete information in proforma were excluded.

A person with medical background was trained to extract required data. Data were entered in Microsoft excel spreadsheet and imported in SPSS 15.0 software for analysis. Frequencies and proportions were enlisted. To test associations Chi squared test was used for qualitative variables and student's ' $t$ ' test for quantitative variables.

\section{Definitions used}

EMS: Services that treat emergency medical conditions by rapid assessment, timely provision of appropriate interventions and promptly transport them to the nearest appropriate health facility by ambulance continuing monitoring/intervention/management. ${ }^{5}$

Scene: Place of the emergency situation.

Destination: Hospital or other treatment facility.

GCS: Calculated by summing up scores for eye, motor, verbal responses of the patients. Max GCS score as 15 represents good general condition. Categorised as $<=8$ : Severe, 9-12: Moderate, $>=13$ : Mild'. . $^{15}$

\section{RESULTS}

We recruited total 849 patients who utilized EMS during the year 2014 fulfilling the inclusion criteria.

\section{General characteristics}

$39.75 \%$ (329/849) were females, $61.0 \%$ (520/849) were males. Mean age 62.56 years $( \pm 20.76)$. $75 \%$ patients were above 55 years. $96.1 \%$ (819/849) emergencies were from Pune only, remaining were from various districts in Maharashtra. $3.42 \%$ (29/849) were from low socio-economic status and made free of charge by the hospital.

$4.9 \%$ (42/849) were from rural area, $2.1 \%$ (18/849) were residing in urban slum, $92.6 \%$ (789/849) were from urban area. In majority, $58.5 \%$ cases ambulance services reached at scene within 15 minutes, in $75 \%$ cases within 25 minutes of the call received. $59.4 \%$ emergencies reached to destination within 30 minutes while $84.4 \%$ within 45 minutes. It took longer time to arrive at scene and destination as kilometers from scene to destination exceeded.

\section{Chief complaints}

Chef complaints were categorized as shown in Fig 1. Major Chief complaints (Fig 1) noted from patients were altered sensorium, severe breathlessness and severe chest pain/ palpitations and or sweating.

\section{Severity of emergency patients}

$28 \%$ of the patients were in severe category while majority (62\%) was in mild to moderate category of severity according to GCS scale (Fig 2).

Fig. 3 shows $49.7 \%$ (152/306) patients with altered sensorium as a major chief complaint were in severe category of GCS score. It was significantly higher than among patients who were not having it as a major chief complaint i.e. $13.2 \%$ (60/453).

\section{Major outcomes of EMS}

Highest proportion, 37.5\% (318/849) was shifted to ICU, DMH for further management (Table 1). 13.5\% (115/849) study subjects died at the scene before/ after arriving EMS. They were excluded from further analysis. (Fig 4)

\section{Mortality and severe GCS}

As shown in Fig 4, 9.7\% (53/547) critical patients with mild to moderate GCS died while $12.3 \%$ (27/212) critical patients with severe GCS died during the course of management. (Fig 5, Table 1). Difference was not statistically significant $(p=0.220)$.

Deaths according to severity among different chief complaints

Highest mortality was noted among patients presenting with chief complaints of anuria, retention of urine (XII: 22\%) ultimately diagnosed to have chronic kidney failure, miscellaneous that could not be classified under 1 category (XIV: 21\%) and high grade fevers with or without rash (IX: 18\%). For severe condition, highest mortality was among patients with road traffic accidents (VIII: $9 \%$ ), seizures (XI: 7\%) and severe/persistent chest pain with seating (I: 5\%). (Fig 6)

Table1: Association of GCS categories and mortality

\begin{tabular}{lccc}
\hline GCS & \multicolumn{2}{c}{ Deaths } & Total \\
\cline { 2 - 3 } & Yes (\%) & No $(\%)$ & \\
Severe GCS & $27(12.3)$ & $185(87.7)$ & $212(100)$ \\
Mild and moderate GCS & $53(9.7)$ & $494(90.3)$ & $547(100)$ \\
Total & $80(10.4)$ & $679(89.6)$ & ${ }^{*} 759(100)$ \\
\hline \multicolumn{2}{c}{${ }^{*}$ deaths at scene before arrival of EMS excluded. $(\mathrm{p}=0.220, \mathrm{OR}=1.266,95 \% \mathrm{Cl}=0.814-1.969)}$.
\end{tabular}




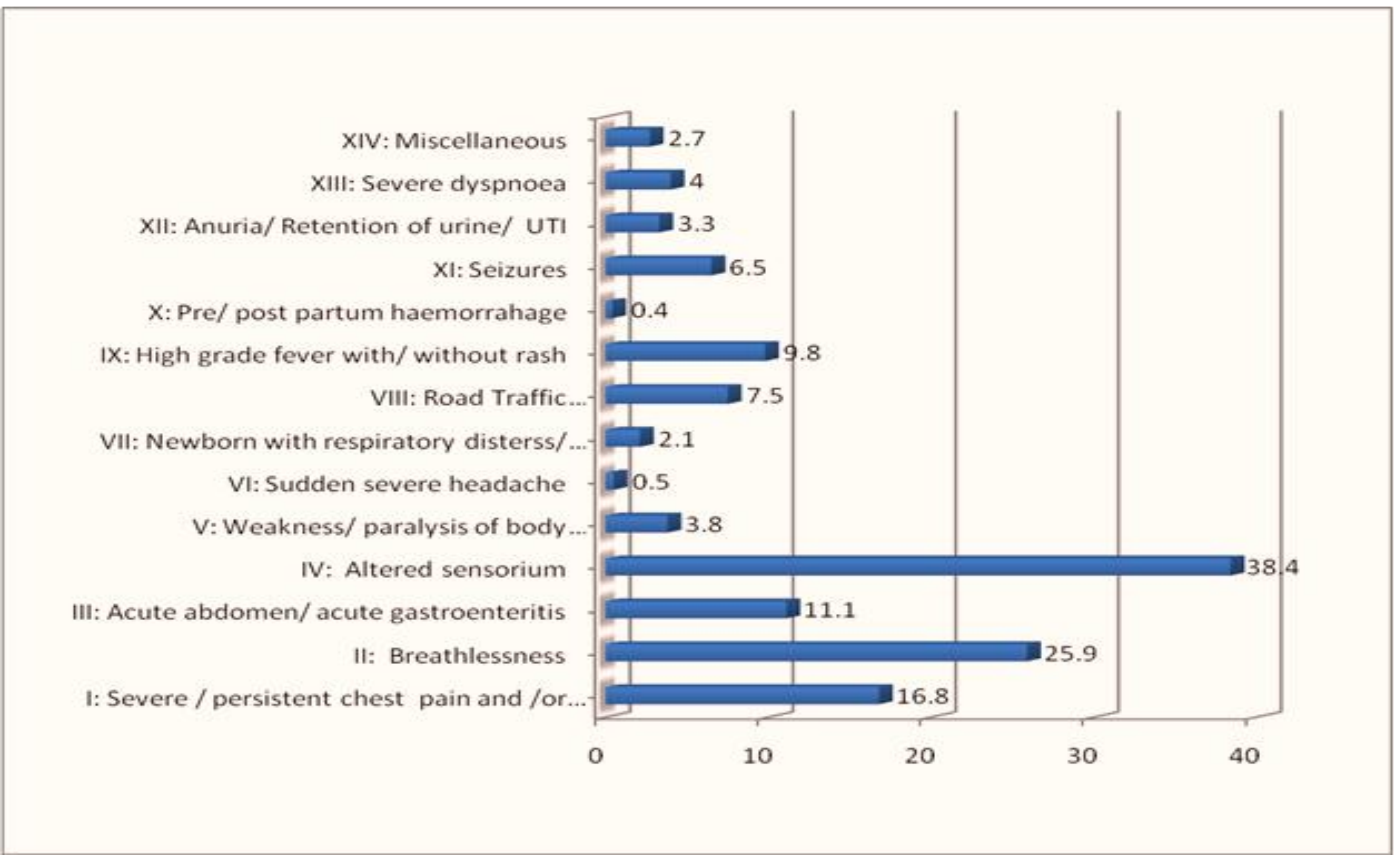

Fig 1: Percentage of emergencioes according to major symptoms
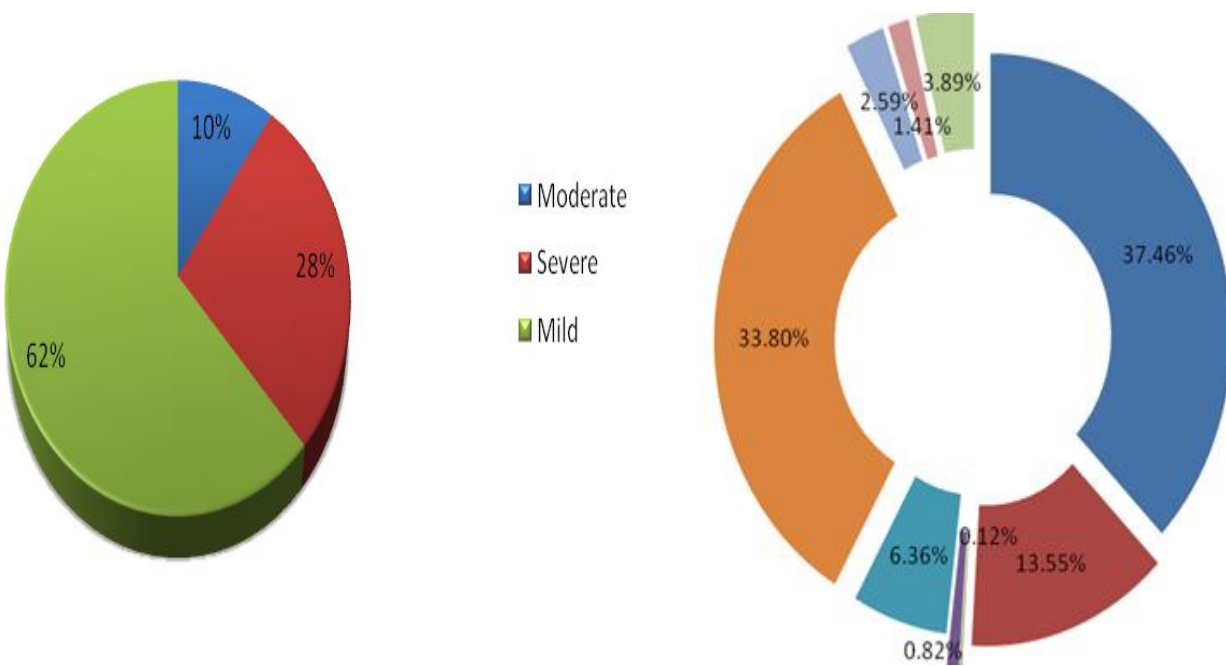

mICU of DMH

Deaths at the scene

Deaths in ambulance

Under observation in emergency room

a Shifted to wards

= Shifted to other hospital

For investigations

Fig 2: Severity of EMS patienents according to Glassgowcoma scale

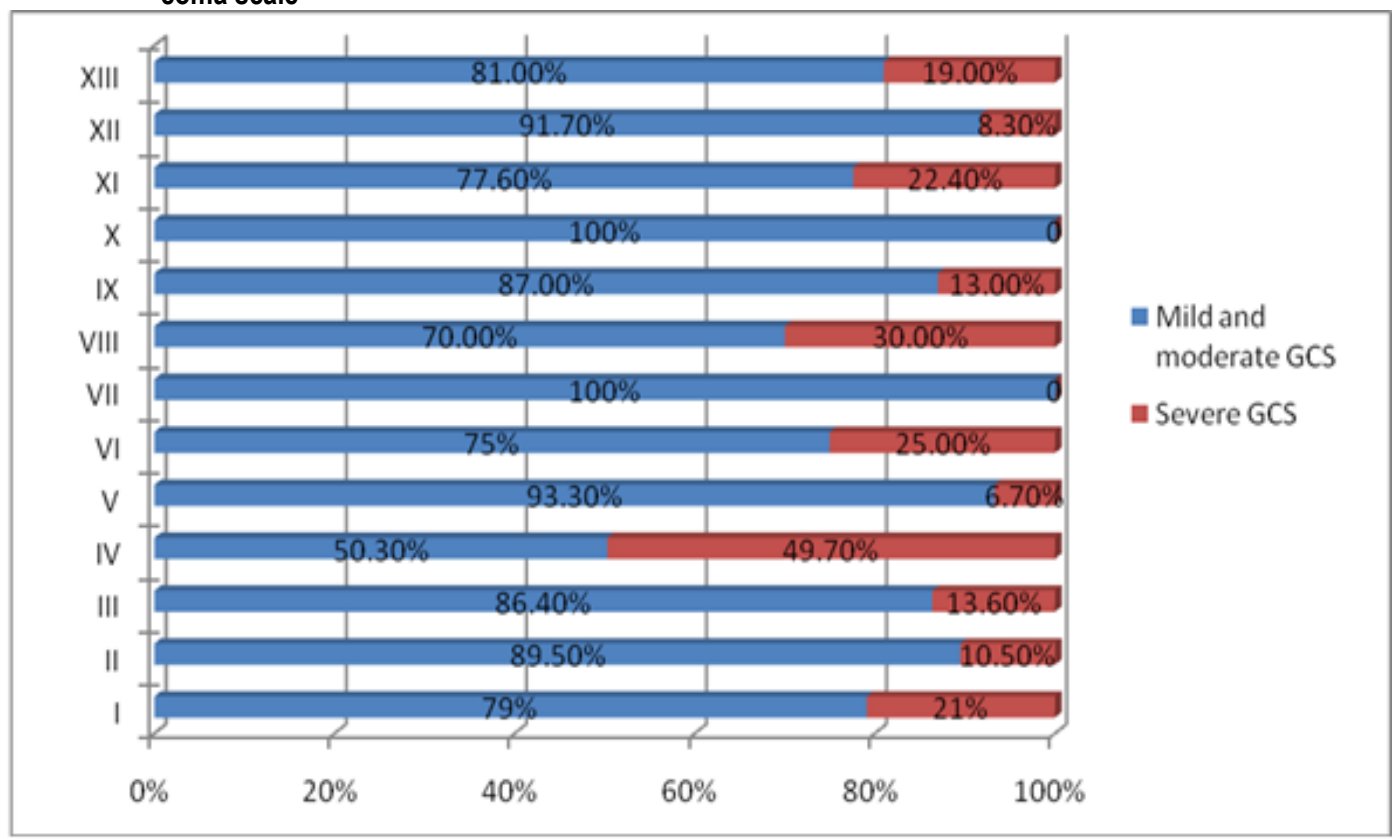

Fig 3: Percentage of severe \& mild / moderate GCS among categories of chief compliants (Categories according to Fig 1) 


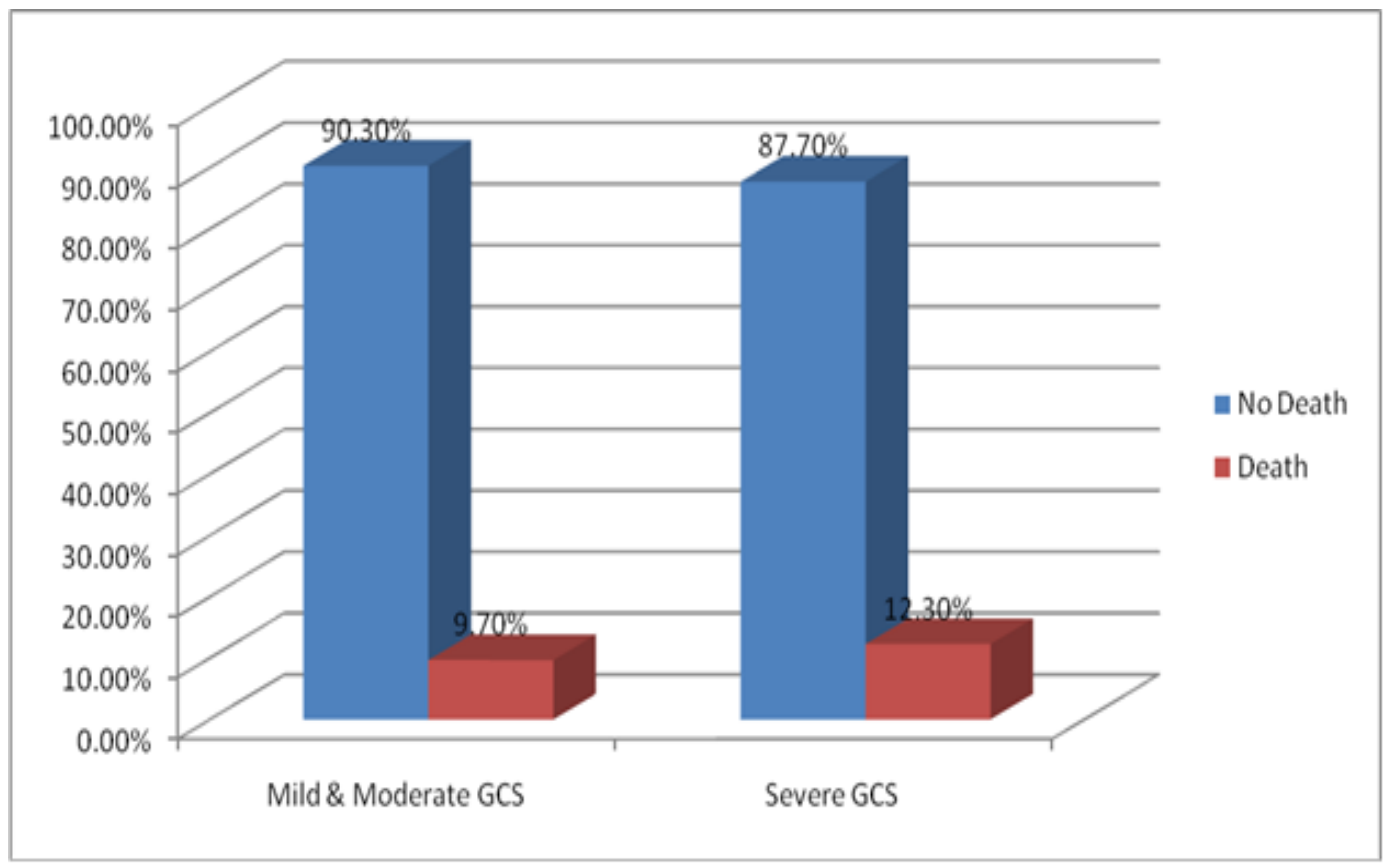

Fig 5: Percentage of Deaths among GCS Categories

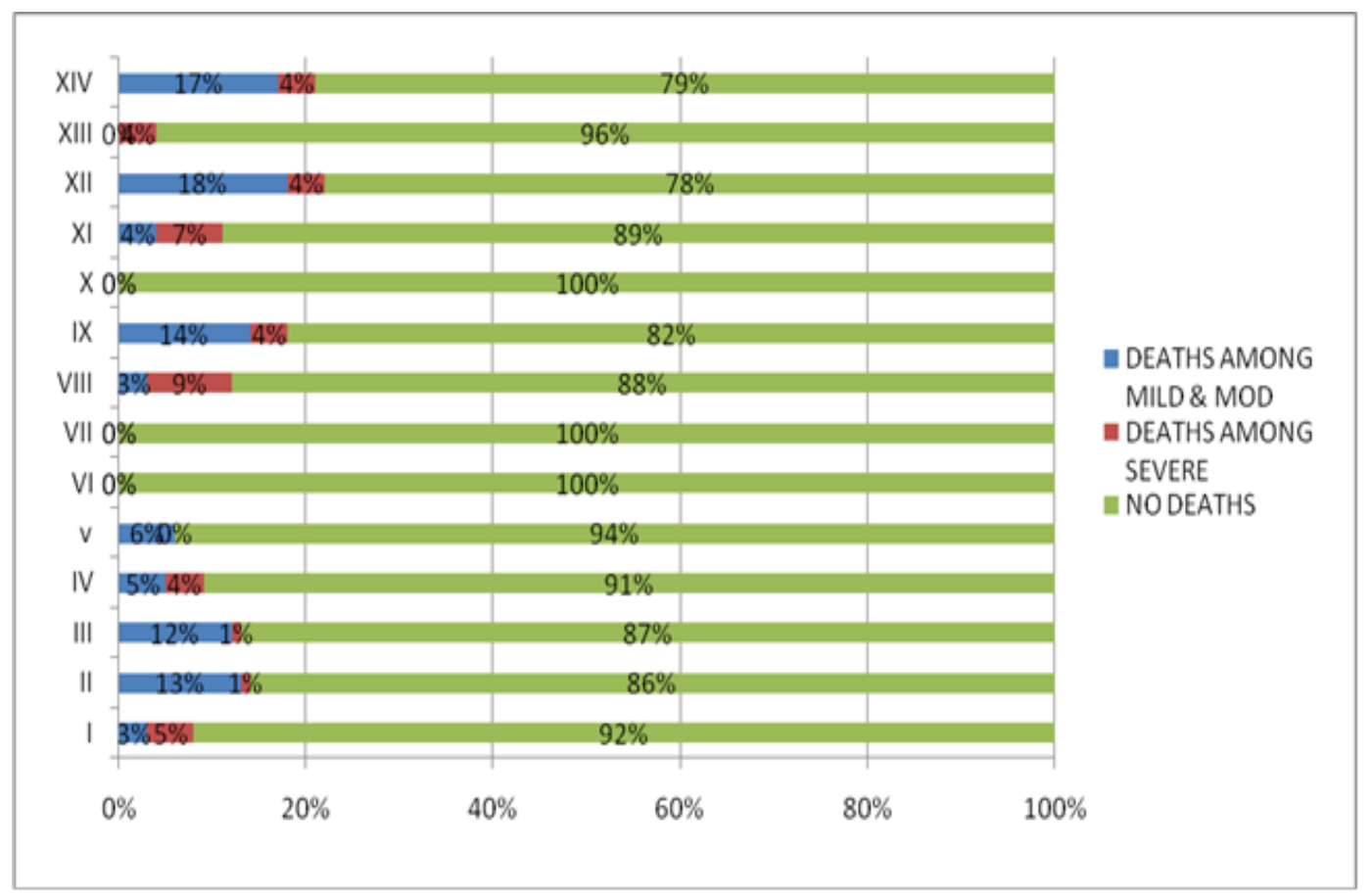

Fig 6: Deaths according to severity among different chief complaints

\section{DISCUSSION}

There exists a linear relationship between GCS score and the odds of mortality. ${ }^{16}$ Thus, Mortality among patients with altered sensorium and severe GCS $(<=8)$ is expected to be more than mortality among patients with mild- moderate GCS (9->=13).

In the present study, mortality among patients with severe GCS utilizing EMS was also more than mortality among patients with mild-moderate GCS but the difference was not statistically significant $(p=.297)$. It re-iterates the efficacy and importance of EMS to manage critical patients specially with severe GCS. Though, the major chief compliant was altered sensorium (Fig 1, category IV) (38.4\%) and percentage of patients with severe GCS was also highest (49.4\%) among this category of chief complaint (Fig 3), deaths were only 4\% (Fig 5). Effective utilization of EMS in
Golden Hour proved to be successful to decrease mortality among this set of study subjects.

RTA is emerging epidemic in India. ${ }^{17}$ In present study, Highest percentage of deaths among severe category were recorded in patients with road traffic accidents (VIII) and seizures (XI) (Fig 5, $9 \%$ and $7 \%$ respectively). Globally, it is $8^{\text {th }}$ leading cause of mortality among young people (15-29 years). ${ }^{17} 44 / 849$ patients were in this age group, 15/44 were victims of RTA, and 1/15 succumbed to death.

When one of the three components of GCS is not testable then a valid total cannot be calculated. Drug use, alcohol intoxication, shock or low blood oxygen can alter patients' level of consciousness. ${ }^{18}$ Though, very few patients (3/849) were under the influence of alcohol or drug users, these factors can lead to 
inaccurate GCS score. ${ }^{19}$ Language, cultural and intellectual differences can interfere assessment of one or more component of the scale. ${ }^{20}$ It was minimized as our ambulance personals were from the same community and geographical area.

GCS helps to predict outcome of critically ill patients and to determine resource allocation for patients' management. ${ }^{21}$ But, there are huge variations in outcome of patients with same GCS score. Along with GCS other scales can also be utilized to assess emergency patients like APACHE (Acute physiology and chronic health evaluation) or NVPS (Nonverbal pain scale) for patients in whom verbal component of GCS can't be scored or wherever appropriate. We observed no association of mortality with age >=61, gender, rural- urban or semiurban residence and presence of co-morbidities ( $p=0.305,0.322,0.211,0.167$ respectively). Presence of co-morbidities was also not associated with severe GCS ( $p=0.436)$.

Overall, mortality among critical patients with severe GCS was $12.3 \%$ which was much lower than what previous studies of critically ill patients with severe GCS reported (19-65.3\%), 20,22 but majority of these studies are restricted to traumatic brain injury patients. It also did not differ significantly from mortality in critical patients with mild-moderate GCS.

In majority of the patients (75\%) EMS reached at scene within 25 minutes the call received. It took longer for patients residing places for from Pune. In our study time required to arrive at scene $\geq 25$ minutes was not associated with any mortality $(p=0.337)$. EMS of present hospital is working efficiently from timely reaching at the scene to managing the critical patient at the scene and during transportation. Inspite of that, such calls can be re-directed to other EMS services and responsive agencies nearby the patient's place.

Thus, Emergency medical services help to reduce mortality among severe category of to the extent that reported in mild to moderate category. Patients with road traffic accidents need other provisions for prompt \& effective management. Relatives or persons accompanying known seizure patients can be educated about emergency measures taken in seizure episodes.

Study is useful to get insight of patients calling emergency medical services from purpose of call to their outcome. Study points need of severity assessment of patient on call itself so that appropriate level of ambulance can be dispatched with advising other measures to manage till ambulance arrives to manage emergencies resource poor settings which is particularly useful EMS systems arising there.

\section{REFERENCES}

1. Das AK, Gupta SB, Joshi SR, Aggarwal P, Murmu LR, Bhoi $S$ et al. White Paper on Academic Emergency Medicine in India: INDO-US Joint Working Group. JAPI 2008 October; 56: 789-97.

2. Park K. Parks textbook of preventive \& social medicine. Chapter 5 ; epidemiology of communicable diseases, I. Respiratory infections: Tuberculosis. 22nd ed. P.166

3. A Xavier Raj. Saving lives through rural ambulance services: Experiences from Karnataka and Tamil Nadu states, India. Transport and Communications Bulletin for Asia and the Pacific2014: 84; 52.

4. Subhan I, Jain A. Emergency care in India: the building blocks. Int J Emerg Med. 2010 Dec; 3(4): 207-211.

5. Kobusingye OC, Hyder AA, Bishai D, Joshipura M, Hicks ER, et al. (2006) Emergency Medical Services. In: Jamison DT, et al., editor. Disease Control Priorities in Developing Countries. 2nd ed. New York and Oxford: Oxford University Press.
6. Potluri P. Emergency services in India. Available from: Asian Hospital \& Healthcare management., Hydrabad, India. Accessed on 3rd May 2016. 7. Bhat R, Hudson K, Sabzevari T. An evidence-based approach to severe traumatic brain injury. EB Medicine 2008;10.

8. Jones C. Glasgow coma scale . Am J Nurs. 1979 Sep; 79(9):1551-3.

9. Gill M, Reilley DG, Green SM. Interrater reliability of Glasgow Coma Scale Scores in the Emergency Department. Ann Emerg Med. 2004; 43:215-23.

10. Predicting outcome after traumatic brain injury: practical prognostic models based on large cohort of international patients. MRC CRASH Trial Collaborators, Perel P, Arango M, Clayton T, Edwards P, Komolafe E, Poccock S, Roberts I, Shakur H, Steyerberg E, Yutthakasemsunt S; BMJ. 2008 Feb 23; 336(7641):425-9.

11. Assessment of coma and impaired consciousness. A practical scale. Teasdale G, Jennett B Lancet. 1974 Jul 13; 2(7872):81-4.)

12. How to measure GCS. Available from: Emergency Medical Paramedic 2010-13.

13. Giving EMS its due recognition. Express healthcare management June 2006.

14. Anuradha Mane. In the nick of time. The Indian Express. PuneNewsline; Monday July 172006.

15. Lankova A. The Glasgow Coma Scale: clinical application in Emergency Departments. Emergency Nurse 14 (8): 30-5 2006.

16. Ting HW, Chen MS, Hsieh YC, Chan CL. Good mortality prediction by Glasgow Coma Scale for neurosurgical patients. J Chin Med Assoc,2010 Mar; 73(3):139-43.

17. Kalaivani Annadurai, Geetha Mani, Raja DanasekaranIndian. Recurring tragedy of road traffic accidents in India: Challenges and opportunities. J Crit Care Med. 2015 Jul; 19(7): 434-435.

18. Meredith W, Rutledge R, Fakhry SM, Emery S, Kromhout-Schiro S. The conundrum of the Glasgow Coma Scale in intubated patients: a linear regression prediction of the Glasgow verbal score from the Glasgow eye and motor scores. J Trauma. 1998; 44:839-44; discussion 844-5.

19. Healey C, Osler TM, Rogers FB, Healey MA, Glance LG, Kilgo PD, Shackford SR, Meredith JW. Improving the Glasgow Coma Scale score: motor score alone is a better predictor. J Trauma. 2003 Apr;54(4):671-8; discussion 678-80.

20. Nursing Practice Review. Forty years on: updating the Glasgow Coma Scale. Nursing Times 2014: $110 ; 42$. Available from: www.nursingtimes.net; accessed on 3.5.2016.

21. Steven M. Green. Cheerio, Laddie! Bidding Farewell to the Glasgow Coma Scale. Annals of Emergency Medicine2011: 58; 5, p 427-30.

22. McIntyre A, Mehta S, Aubut J, Dijkers M, Teasell RW. Mortality among older adults after a traumatic brain injury: a meta-analysis. Brain Inj. 2013;27(1):31-40.

\section{Source of Support: Nil.}

\section{Conflict of Interest: None Declared.}

Copyright: (c) the author(s) and publisher. IJMRP is an official publication of Ibn Sina Academy of Medieval Medicine \& Sciences, registered in 2001 under Indian Trusts Act, 1882.

This is an open access article distributed under the terms of the Creative Commons Attribution Non-commercial License, which permits unrestricted non-commercial use, distribution, and reproduction in any medium, provided the original work is properly cited.

Cite this article as: Rajhans Prasad A, Kulkarni Priya Y, Kelkar Dhananjay S, Jog Sameer A, Ranade Gouri, Utpat Sonal, Hande Varsha. Assessment of Mortality among Patients Utilizing Emergency Medical Services of Tertiary Care Hospital, Pune. Int J Med Res Prof. 2016; 2(3):174-78. 